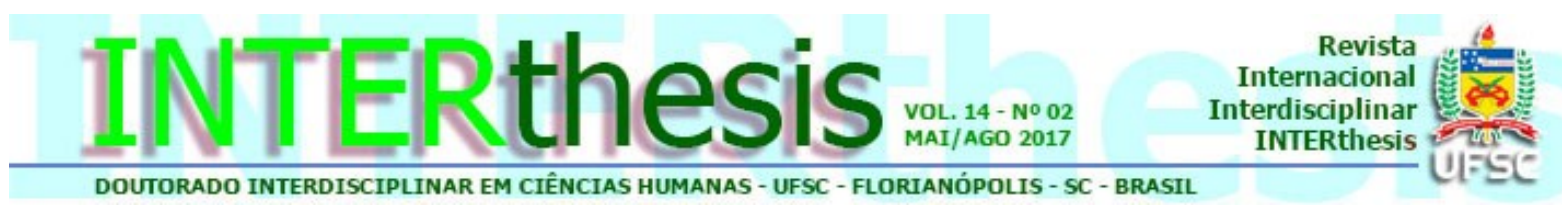

\title{
A INTERDISCIPLINARIDADE NA SOCIEDADE MIDIATIZADA: UMA DICOTOMIA IMPERATIVO-PROBLEMA NOS ESTUDOS SOBRE CULTURA
}

\author{
Denise Rosana da Silva Moraes ${ }^{1}$ \\ Claudia Maria Serino Lacerda Muniz ${ }^{2}$ \\ Francielli Rubia Poltronieri ${ }^{3}$
}

\section{Resumo:}

Este artigo analisa, com base nos Estudos Culturais, a razão pela qual a interdisciplinaridade se impõe, na sociedade contemporânea, como imperativo e, ao mesmo tempo, como desafio nos estudos sobre cultura. Ela é uma exigência, pelos efeitos que a mídia tem provocado nos processos de constituição identitária das nações latino-americanas, e um problema, pelas frustrações teóricas contemporâneas que não têm dado conta de organizar e explicar as novas diversidades. Essa dicotomia não se trata de uma questão de método ou didática, embora se manifeste, com maior ênfase, neste nível, mas, fundamentalmente, de uma questão estrutural, herdada do modelo tradicional de ciência, que acostumou os pesquisadores a construírem, isoladamente, seus objetos de estudo. Neste contexto, a análise é realizada por meio da revisão de literatura e nas sendas da abordagem qualitativa de pesquisa.

Palavras-chave: Estudos Culturais. Cultura. Interculturalidade, Interdisciplinaridade. Mídia.

\section{INTRODUÇÃO}

Este artigo reflete acerca das dimensões da interdisciplinaridade ainda não enfatizadas, suficientemente, no contexto da sociedade midiatizada, no sentido de apreendê-la, ao mesmo tempo, como necessidade e problema nos estudos sobre cultura.

Como uma imposição do momento atual, a interdisciplinaridade desafia novos

\footnotetext{
1 Doutora em Educação pela Universidade Estadual de Maringá, Maringá, PR, Brasil. Professora da Universidade Estadual do Oeste do Paraná no Centro de Educação, Letras e Saúde, Campus de Foz do Iguaçu. Docente do Curso de Pedagogia do Mestrado e Doutorado Acadêmico Interdisciplinar em Sociedade, Culturas e Fronteira em Foz do Iguaçu, PR, Brasil E-mail: denisepedagoga@gmail.com 2 Mestre em Sociedade, Cultura e Fronteiras pela Universidade Estadual do Oeste do Paraná, Campus de Foz do Iguaçu, Foz do Iguaçu, PR, Brasil. Secretária Executiva da Universidade Federal da Integração Latino-Americana.

E-mail: claudialacerda84@gmail.com

${ }^{3}$ Mestranda do Programa de Pós-Graduação Interdisciplinar em Sociedade, Cultura e Fronteiras na Universidade Estadual do Oeste do Paraná, Campus Foz do Iguaçu. Professora de Sociologia do quadro próprio do Magistério do Estado do Paraná, Foz do Iguaçu, PR, Brasil. E-mail: franciellirubia@hotmail.com
} 
olhares para a cultura, desautorizando as justificativas para o seu estudo em separado da mídia, dada a influência desta última, nos processos de constituição identitária das nações, aqui restritas ao cenário latino-americano. Por outro lado, apresenta-se como um problema epistemológico, pela dificuldade das áreas, que se ocupam deste estudo, em organizar e explicar as novas diversidades, desde que a globalização passou a interconectar, simultaneamente, quase todo o mundo, criando e/ou apresentando novas diferenças e desigualdades.

Assim, os objetivos complementares desta pesquisa residem em: apresentar a modernidade tardia como mudança de paradigma e desestabilização da identidade cultural; evidenciar a necessidade de discussão conjunta das questões relacionadas à cultura e à mídia; apontar as causas das frustrações teóricas contemporâneas a respeito dos estudos sobre a cultura; e assinalar, dentro dos limites de um artigo científico, os possíveis desafios impostos à Sociologia, à Antropologia e à Comunicação - principais campos de investigação da categoria "cultura" - para dar conta das complexidades deste período híbrido que demanda análises amplas e interdisciplinares.

Essas reflexões delineiam a discussão central deste artigo, que é a necessidade de diálogo interdisciplinar da cultura e da mídia, diante da influência desta última na contemporaneidade. Tal posicionamento teórico é compartilhado por Verón (2001), para quem o funcionamento das instituições, das culturas, das práticas sociais, na "sociedade midiatizada", estrutura-se em relação direta com a existência das mídias. Com efeito, produz-se novos sentidos à cultura, às condutas sociais e aos valores, inaugurando modelos identitários que confrontam com os padrões de sociabilidades já instituídas. Tal transformação, para Carneiro (2016), demanda novas formas de fazer pesquisas, cabendo uma nova ontologia e epistemologia que auxiliem na compreensão dos fenômenos da atualidade, marcada pela imbricação de tecnologias midiáticas, atores sociais, diversidade, meios de comunicação tradicionais e sociedades.

Nesse sentido, a exposição foi estruturada em três partes: na primeira é apresentada a metodologia adotada; na segunda, o ponto de partida da reflexão proposta - a pós-modernidade ou modernidade tardia - que discute a identidade, no cenário atual, como dinâmica e instável; na terceira, o tema central da pesquisa: a necessidade de discussão conjunta dos estudos sobre a cultura e a mídia, trazendo 
para o nível do debate os avanços e as dificuldades ainda enfrentadas para a compreensão destas categorias de forma interdisciplinar.

\section{PROCEDIMENTOS METODOLÓGICOS}

Tão necessário quanto definir o objeto e os propósitos de uma investigação, é a capacidade de conduzi-la, adequadamente. Assim, um estudo que se pretenda científico, precisa possuir densidade teórica e metodológica a fim de assegurar, no exercício epistemológico, a apreensão da realidade, assim como fez Paulo Freire, ao emergir sua proposta de alfabetização de um contexto real, factível.

Essa preocupação corrobora as questões metodológicas e teóricas que norteiam a pesquisa científica nas ciências humanas, conforme Bachelard (1989) que expressa que o cientista, ao realizar sua investigação, produz resultados e conhecimentos e elabora uma filosofia, pois ao interagir com o objeto, anuncia uma nova concepção de mundo; portanto, uma epistemologia.

Mas, nem sempre, tais investigações são reconhecidas no meio científico, sobretudo, quando oriundas de áreas de pouco status acadêmico. Para Bronowski (1977), um dos mais deletérios preconceitos, nesse sentido, refere-se à compreensão, por exemplo, da Arte e da Ciência como campos opostos. Logo, não teria sentido pensar a pesquisa de forma interdisciplinar, pois aquela não mereceria crédito em relação ao rigor científico que a ciência tradicional impõe e que demanda certa austeridade.

Assim, "quando o pesquisador almeja adotar uma atitude interdisciplinar, diante da produção do conhecimento, por mais paradoxal que possa parecer, as dificuldades e as possibilidades aumentam" (TORDINO, 2014, p. 23). Faz-se necessário deixar claro, portanto, o percurso metodológico desta pesquisa: os dados foram obtidos por meio de exame bibliográfico, nas sendas da abordagem qualitativa de pesquisa; o estudo restringiu-se ao universo de bibliografias sobre interdisciplinaridade, mídia e cultura, tendo sido realizadas análises transversais de conteúdo. Como marco orientador, evidenciou-se o campo axiológico dos Estudos Culturais realizados por Stuart Hall, Douglas Kellner, Jesús Martín-Barbero e, sobretudo, Néstor García Canclini. 
Ao adentrar na diversidade metodológica e epistemológica, que articula práticas, concepções e conflitos na pesquisa, Gamboa (2007) expressa que não há somente discordância da visão positivista, mas, uma polêmica acerca das hegemonias e dos reducionismos da técnica, compreendida como cumprimento de ritual de pesquisa. Tal concepção, de certa forma, orienta esta pesquisa que considera um objeto de estudo como multidimensional, sendo passível de várias interpretações e ângulos de análise.

\section{A PÓS-MODERNIDADE (OU MODERNIDADE TARDIA) E A MUDANÇA DE PARADIGMAS: A DESESTABILIZAÇÃO DA IDENTIDADE CULTURAL}

O mundo vivencia uma série de mudanças em suas estruturas políticas, sociais, culturais e econômicas que está desestabilizando as referências do sujeito de um lugar estável e definido no mundo social. Esse novo contexto, denominado por Hall (2006, p. 9) de "pós-moderno" e por Jameson (2006, p. 20) de "modernidade tardia", incita novas discussões sobre o termo "identidade", pois, essas transformações estão abalando a ideia que temos de nós próprios como sujeitos. Uma característica importante deste período, pontuada por Jameson (2006), diz respeito à abolição de algumas fronteiras, que se dá pela erosão da distinção entre a cultura da elite e a cultura popular. Este é um momento bem particular de periodicização, que "trata-se de correlacionar o surgimento de novos aspectos formais na cultura com o surgimento de um novo tipo de vida social e de uma nova ordem econômica". (JAMESON, 2006, p. 20)

A mudança dos paradigmas modernos trouxe à tona novos processos identitários, tais como a desestabilização, a heterogeneidade e a descontinuidade, pressupostos que representam elementos da sociedade como ela realmente é. Com efeito, há, para o sociólogo Anthony Giddens (2002), várias interpretações sobre a formação das identidades contemporâneas, as quais resultam das subjetividades do mundo moderno. Ele parte de um conceito de identidade pessoal, ou seja, uma "reflexidade da modernidade que se estende ao núcleo do eu". Autores provenientes dos Estudos Culturais, como Douglas Kellner (2001) e Néstor Garcia Canclini (2009), partem da ideia da existência de uma identidade coletiva, ligada a sistemas culturais específicos. Assim, entendem que a identidade é construída por meio de 
um conjunto de significados socializados, estando ligada às discussões sobre identidade coletiva, identidades regionais e/ou nacionais.

Tais discussões foram, durante muito tempo, relegadas a segundo plano, pois, acreditava-se que as identidades eram consequências sociais ou produções individuais. Logo, não se tratava o termo com a devida importância. Com o caminho aberto pelos Estudos Culturais, as identidades passaram a ser compreendidas como múltiplas e fragmentadas, colocando em "xeque" muitas certezas construídas durante a modernidade. Costa (2009) afirma que as identidades, sob a ótica dos Estudos Culturais, estão imersas em relações de poder e, portanto, inscritas nas políticas culturais da identidade analisadas, necessariamente, nas arenas do seu próprio significado. Douglas Kellner (2001), consoante à Costa, expressa que os discursos pós-modernos envolvem a problematização e a desconstrução das noções de identidade. Para ele:

[...] O sujeito autônomo e autoconstituído, realização final no indivíduo moderno, de uma cultura do individualismo, está se fragmentando e desaparecendo devido aos processos sociais que nivelam as individualidades, na sociedade racionalizada, burocratizada, consumista e dominada pela mídia (KELLNER, 2001, p.298).

Stuart Hall (2004), um dos precursores dos Estudos Culturais, defende a necessidade de que as manifestações culturais sejam interpretadas no âmbito de um circuito de produção cultural e distingue três concepções de identidade que foram sendo construídas e desconstruídas, historicamente. A primeira, tem suas bases no lluminismo e compreende o sujeito como centrado e racional, pautado nos interesses individuais. A segunda, Hall chama de sujeito sociológico, que forma sua identidade a partir da interação com a sociedade moderna e suas complexidades. A última trata do sujeito pós-moderno, aquele destituído de identidade fixa ou permanente; um sujeito que se torna fragmentado e compreende várias identidades, sendo, por vezes, contraditórias ou não resolvidas. Assim "a identidade torna-se uma celebração móvel, formada e transformada continuamente em relação às formas pelas quais somos representados ou interpelados nos sistemas culturais que nos rodeiam" (HALL, 1987, apud HALL, 2004 p. 12).

Tais concepções demandam reflexões acerca da cultura, a qual está, intimamente, relacionada ao processo de construção identitária, conforme aponta Cuche:

Há uma estreita relação entre a concepção que se faz de cultura e a concepção que se tem de identidade cultural. Aqueles que integram a R. Inter. Interdisc. INTERthesis, Florianópolis, v.14, n.2, p.01-18 Mai.-Ago. 2017 
cultura como uma segunda natureza, que recebemos de herança e da qual não podemos escapar, concebem a identidade com um dado que definiria de uma vez por todas o indivíduo e que o marcaria de maneira quase indelével. [...] Em uma abordagem culturalista, a ênfase não é colocada sobre a herança biológica, não mais considerada como determinante, mas na herança cultural, ligada à socialização do indivíduo no interior de seu grupo cultural (CUCHE, 1999 p. 179).

Nesse sentido, o autor enfatiza que a formação da identidade está intimamente ligada à cultura a qual o sujeito pertence, pois é por meio dela que ele se percebe como integrante de uma nação, de uma comunidade ou de um grupo social. Assim, ao discuti-la, no contexto da América Latina, Néstor García Canclini, em sua obra Diferentes, Desiguais e Desconectados (2009), propõe a compreensão não de uma cultura latino-americana única, mas de um espaço sociocultural onde coexistem diversas identidades e culturas.

Partindo deste entendimento, o termo "cultura" parece demandar reconceituação, dada a proliferação de sentidos atribuídos à palavra, ao longo dos anos, desde que a globalização passou a interconectar, simultaneamente, quase todo o mundo, por meio das tecnologias da informação, deslocando as identidades culturais nacionais.

\section{CULTURA E MÍDIA: UMA DISCUSSÃO INSEPARÁVEL}

Há décadas, aqueles que realizam estudos sobre a cultura vivenciam um contexto de imprecisões. Segundo Canclini (2009), os antropólogos Alfred Kroeber e Clyde K. Klukhohn recolheram, em 1952, quase trezentas maneiras de definir o termo. Assim, o autor adverte sobre os riscos de não se saber do que se fala, em razão da dispersão de referências à palavra, resultantes da globalização, da economia e da informação.

Entre as diferentes narrativas sobre a cultura, o autor destaca: aquelas que a abordam como sendo "o acúmulo de conhecimentos e aptidões intelectuais e estéticas" (CANCLINI, 2009, p.37) e as que reduzem a cultura a tudo aquilo que é criado pelo homem, ou seja, tudo o que não é natureza. No entanto, uma das definições que melhor ilustra o contexto atual, compartilhada por autores de diversas áreas do conhecimento - como sociólogos e antropólogos - é apontada por Canclini como: "a cultura abarca o conjunto de processos sociais de produção, circulação e consumo da significação na vida social" (CANCLINI, 2009, p. 41).

R. Inter. Interdisc. INTERthesis, Florianópolis, v.14, n.2, p.01-18 Mai.-Ago. 2017 
Partindo deste pressuposto, torna-se difícil estudar cultura sem relacioná-la à mídia, cuja influência nos processos de circulação e consumo de significados, bem como de construção identitária é extremamente grande. Douglas Kellner, articulando diferentes teorias - marxista, gramsciana, estruturalista - afirma que não há justificativas para o estudo em separado dessas categorias, ressaltando que:

\begin{abstract}
A cultura da mídia é a cultura dominante hoje em dia; substituiu as formas de cultura elevada como foco da atenção e de impacto para grande número de pessoas. Além disso, suas formas visuais e verbais estão suplantando as formas da cultura livresca, exigindo novos tipos de conhecimentos para decodificá-las. Ademais, a cultura veiculada pela mídia, transformou-se numa força dominante de socialização, suas imagens e celebridades substituem a família, a escola e a Igreja, como árbitros de gosto, valor e pensamento, produzindo novos modelos de identificação e imagens vibrantes de estilo, moda e comportamento (KELLNER, 2001, p. 27).
\end{abstract}

Por esta razão, dialoga-se cada vez mais sobre "culturas virtuais", as quais resultam, segundo Jesus Martín-Barbero (2014, p. 22) "das mediações entre cultura e tecnologia." De acordo com o autor, elas se constituem como sistemas simbólicos de intercâmbio por meios dos quais se configuram sentidos coletivos, modificando a sensibilidade dos sujeitos, bem como suas formas de representar o mundo e relacionar-se com os outros.

Logo, as informações veiculadas pelos meios de comunicação de massa contribuem para uma redefinição de valores, interesses e hábitos sociais, concorrendo com as instituições sociais, no que concerne ao processo de constituição de identidades, seja local ou global. Por isso, as discussões sobre a mídia não podem ser excluídas deste debate, pois, mais do que meios, a comunicação, incluindo a midiatizada, "é hoje questão de mediações, isto é, de cultura, e deve ser vista como uma camada espessa de crenças, valores e tradições" (MARTíN-BARBERO, 1997, p.19).

Assim, Canclini (2009, p. 24 e 25) recomenda a compreensão do termo cultura não como um substantivo, atrelado a um objeto ou sistema de sentidos, mas como um adjetivo - o cultural - para dar conta das significações e abrangências não contempladas no conceito tradicional da palavra. A adoção adjetivada do termo amplia tal concepção, o que permite falar em "choque de significados nas fronteiras...", como resultado das intersecções midiáticas. Para tanto, incorpora a noção de cultura redefinida por Abélès, Appadurai e Clifford, entendendo-a como um "sistema de relações de sentido que identifica diferenças, contrastes e comparações.". Tal compreensão demanda, para Canclini, um novo método de

R. Inter. Interdisc. INTERthesis, Florianópolis, v.14, n.2, p.01-18 Mai.-Ago. 2017 
análise: "em vez de comparar culturas que operariam como sistemas preexistentes e compactos, [...] trata-se de prestar atenção às misturas e aos mal-entendidos que vinculam os grupos" (CANCLINI, 2009, p. 25).

Esta concepção remete à noção de interculturalidade, termo ainda em construção, de acordo com Martín-Barbero (2014), para denominar a convergência das distintas identidades culturais. Tal abordagem, não pode ser compreendida ou regulada de cima, à margem dos processos de hibridação cultural, os quais situamse num lugar que transcende o âmbito delimitado pelas fronteiras geopolíticas.

\begin{abstract}
Nessa direção, Canclini (2009, p. 55) expressa que "uma teoria consistente da interculturalidade deve encontrar a forma de trabalhar conjuntamente os três processos pelos quais esta se trama: as diferenças, as desigualdades e a desconexão" Isso torna ainda mais complexo este debate, impondo novos desafios àqueles que estudam a cultura, já que as Ciências Sociais se acostumaram a investigar, separadamente, cada uma destas três categorias. Assim, ao invés de procurar verificar como convergem, ignoram ou se chocam a "cultura comunitária", a "cultura como distinção" e a "cultura.com", tais estudos têm seguido direções opostas:Para as antropologias da diferença, cultura é pertencimento comunitário e contraste com os outros. Para algumas teorias sociológicas da desigualdade, a cultura é algo que se adquire fazendo parte das elites ou aderindo seus pensamentos e gostos; as diferenças culturais procederiam da apropriação desigual dos recursos econômicos e educativos. Os estudos comunicacionais consideram, quase sempre, que ter cultura é estar conectado (CANCLINI, 2009, p. 15 e 16).
\end{abstract}

Tais limitações demandam a exploração, o debate e a intersecção de diferentes contribuições teóricas, ou seja, um trabalho interdisciplinar, para dar conta das complexidades da pós-modernidade, não havendo espaço para a instalação de teorias únicas. Desta forma, Williams (2011) evidencia, ao referir-se às transformações do século XX, que as mídias, como meios sociais de produção, assumiram uma importância nova, na sociedade contemporânea. Logo, é preciso refletir acerca das direções possíveis e viáveis para abordar agora, por meio das intervenções teóricas, os caminhos para se pensar a mídia e suas finalidades comunicativas como centrais e decisivas, neste contexto global.

Trata-se de um grande desafio, já que o paradigma atual, da ciência moderna, não raras vezes, prejudica a percepção do real (como um todo estruturado, que se constrói historicamente), dada a sua rigidez estrutural, que foca a precisão e a particularidade. 


\section{O "EXÍLIO" EPISTEMOLÓGICO COMO HERANÇA DO MODELO TRADICIONAL DE CIÊNCIA}

Os diferentes enfoques de teóricos sociais e comunicacionais, sobre questões relacionadas às identidades culturais, não têm dado conta de explicar as formas globalizadas de interculturalidade que, na perspectiva dos Estudos Culturais, exige que se vá "além do estudo de contatos ocasionais entre culturas e sociedades", abarcando também "as indústrias culturais e outros processos que transcendem as sociedades nacionais" (CANCLINI, 2009, p. 126).

Nesse sentido, Canclini considera, criticamente, três direções teóricas: a) a que destaca as diferenças (étnicas, nacionais ou de gênero), a partir de uma visão absolutista, que valoriza somente os enfoques oriundos da experiência particular; $b$ ) a que coloca no centro das discussões não a diferença, mas a desigualdade: que reduz a análise sociológica das práticas sociais à luta pelo poder, ignorando as diferenças que não derivam, necessariamente, da desigualdade social e; c) a que destaca o papel decisivo da conectividade/ tecnologia nas relações sociais, deslocando a problemática da diferença e da desigualdade para a da inclusão/ exclusão.

Para ele, ao "optar só por aquilo que podia afirmar as diferenças, diminuir a desigualdade ou conectar-nos com as redes estratégicas..." (CANCLINI, 2009, p. 102), acaba-se desviando o foco da teoria social, que demanda análises inter e transdisciplinares:

é difícil imaginar algum tipo de transformação para um regime justo, sem promover políticas (étnicas, de gênero, de regiões), que façam comunicar os diferentes, corrijam as desigualdades (surgidas destas diferenças e das outras distribuições desiguais de recursos) e conectem as sociedades com a informação, com os repertórios culturais, de saúde e bem-estar globalmente expandidos (CANCLINI, 2009, p. 102).

Para elaborar uma teoria que compreenda e organize as formas globalizadas de interculturalidade, o autor busca a essência destas frustrações epistemológicas, aprofundando, para tanto, a visão teórica de dois precursores das Ciências Sociais: Clifford Geertz e Pierre Bourdieu. No seu entendimento, as concepções de ambos ignoram os atores centrais da sociedade globalizada - a indústria cultural e os meios de comunicação de massa - concentrando suas análises no absolutismo das autoafirmações étnicas e em leituras isoladas da realidade. 
Num contexto de globalização, o objeto de estudo mais revelador e questionador das pseudocertezas disciplinares ou etnocêntricas é a interculturalidade. Dessa forma, a hipótese que Canclini chega, ao aprofundar as concepções teóricas dos referidos autores, é a de que os cientistas sociais têm duas grandes tarefas para realizar, a partir do "exílio":

a) permitir que os objetos de estudo e ação de cada campo sejam confrontados, vale dizer, desafiados pelos outros com os quais tenham relação [...]; b) deixar que, dentro da globalização, emerjam as perguntas da interculturalidade, das fronteiras que não caem ou só mudam de lugar, das diferenças e desigualdades não diluíveis na globalização." (CANCLINI, 2009, p. 127 e 128).

Essas tarefas são complexas e demandam, necessariamente, uma postura crítica auto-reflexiva das fortalezas disciplinares. Requer, ainda, a compreensão acerca daquilo que, na literatura, na arte, na mídia e na política, transcende a circulação de bens comerciáveis: produção de conhecimento e informação, defesa de direitos humanos e outras formas pelas quais indivíduos e culturas interagem. Implica, portanto, "converter-se em especialista das interseções" (CANCLINI, 2009, p. 128).

\section{OS ESTUDOS CULTURAIS COMO UMA "SAÍDA DE EMERGÊNCIA" PARA AS "PRISÕES" DA DISCIPLINARIDADE}

As desordens causadas pelo mundo globalizado tornaram porosas as paredes das "prisões" que separavam as áreas do conhecimento. Nesse contexto, são trazidas para o nível do discurso as proposições dos Cultural Studies e dos Estudos Culturais latino-americanos. Estes, "começaram como uma saída de emergência", visando dar espaço aos temas que não se chegavam por meio das "portas especiais" das disciplinas (CANCLINI, 2009, p.152 e 153). Para tanto, fizeram acesso pela porta da Filosofia, que é, essencialmente, porosa e aberta ao diálogo. Atualmente, esta abordagem assemelha-se mais a uma "porta giratória" (CANCLINI, 2009, p. 153), em razão de sua metodologia de análise proposta dialeticamente. Daí a razão deste movimento de ir e vir, visando abarcar tanto as contribuições clássicas quanto as contemporâneas, num repertório de autores citáveis e legítimos, sem sobreposições. 
Entretanto, tal como as demais vertentes, os Estudos Culturais também possuem limitações. Desde o final do século XX, grande parte do debate, nessa linha, tem se concentrado mais em vincular e diferenciar os Cultural Studies e os Estudos Culturais latino-americanos. Atingiu-se, com isso, um nível de intercâmbio teórico fecundo, não se pode negar, permitindo compreender melhor as distintas condições da prática intelectual nos Estados Unidos e na América Latina. Mas, apesar de terem iluminado as relações socioculturais Norte/ Sul, o acervo de bibliografias identificadas como Estudos Culturais ou Cultural Studies contempla pouco as discussões socioeconômicas, políticas e comunicacionais das transformações culturais recentes. O diálogo entre eles tem sido estabelecido por meio da análise de discursos literários e artísticos, com elaboração crítica restrita às universidades. Desta forma, excluem-se das análises, as indústrias de comunicação, as quais, atualmente, evidenciam-se os maiores intercâmbios culturais.

No âmbito editorial, também se verificam lacunas. As editoras espanholas, que controlam o mercado de livros, raramente publicam estudos culturais, antropológicos ou sociológicos de latino-americanos, e quando o fazem, a circulação destes livros é limitada ao país de origem. "Construiu-se a imagem internacional da América Latina como provedora de ficções narrativas, não de pensamento social e cultural" (CANCLINI, 2009, p. 151), a que só se atribui interesse local.

O autor reconhece a importância dos latino-americanistas dos Estados Unidos por prestarem atenção à literatura latino-americana. Para ele, há mais livros de Jesús Martín Barbero, Beatriz Sarlo, Roger Bartra e outros dez estudiosos da América Latina traduzidos à língua inglesa que à espanhola. Preocupa-lhe, no entanto, o fato de ter se tornado mais atraente confrontar autores do Sul com os do Norte que trabalhar, conjuntamente, para renovar a perspectiva sobre a alta cultura e os meios de comunicação, deixando "com fracos suportes sociais o que nos Estudos Culturais houve de projeto estratégico." (CANCLINI, 2009, p. 157).

Jantsch e Bianchetti (2011) atribuem as dificuldades da prática interdisciplinar à lógica da ciência positivista que tem engessado as possibilidades de criação, por parte do indivíduo. Assim, a proposta da interdisciplinaridade acaba prejudicada, já que sua efetivação passa pela transferência da prática homogeneizadora, com foco na disciplina, para uma prática colaborativa. Tudo isso, para Canclini (2009, p. 159), "reformula a agenda clássica dos Estudos Culturais" que implica a necessidade de 
rediscussão - a partir de uma abordagem interdisciplinar - das questões culturais, na América Latina, visando reconstruir a noção de sujeito, para mais além de modelos prontos e engessados.

\section{INTERDISCIPLINARIDADE: UM PARADIGMA EM CONSTRUÇÃO?}

Na sociedade contemporânea, o rompimento com tendências fragmentadoras e desarticuladas do processo de conhecimento, justifica-se pela necessidade de explicação de fenômenos complexos, como a desestabilização da identidade cultural, oriundos, principalmente, das transformações advindas do processo de globalização. É nesse contexto que emerge a interdisciplinaridade, visando transcender a racionalidade positivista e reforçar "os princípios da criatividade e da diversidade (ou diferença)" (JANTSCH e BIANQUETTI, 2011, p. 23). Esta realização integrativa-interativa permite visualizar um conjunto de ações interligadas, de caráter totalizante e isenta de qualquer visão parcelada, contribuindo para superar as atuais fronteiras disciplinares e conceituais. Trata-se, contudo, de uma filosofia em gestação, conforme expressam Raynaut e Zanoni (2011), já que não existe uma teoria sobre a interdisciplinaridade (e não se sabe se um dia será possível alcançála). Mas, isso não significa, que ela constitua uma paradigma em construção, o qual leva a reducionismos e paternalismos, engessando as possibilidades de criação humana. Logo, não há receitas para a sua aplicação, apenas princípios que a norteiam:

Enquanto princípio mediador entre as diferentes disciplinas, não poderá jamais ser elemento de redução a um denominador comum, mas elemento teórico-metológico da diferença e da criatividade. A interdisciplinaridade é o princípio da máxima exploração de cada ciência, da compreensão dos seus limites, mas, acima de tudo, é o princípio da diversidade e da criatividade (ETGES, 1993, apud JANTSCH E BIANCHETTI, 2011, p. 23).

Assim, a interdisciplinaridade não deve ser entendida como um mero "sopão epistemológico e metodológico" (JANTSCH e BIANCHETTI, 2011, p. 28), pois não visa a homogeneização; muito menos deve ser compreendida como um modelo pronto ou imposição, já que não desconsidera a identidade teórica e metodológica dos campos do saber. Ela reclama apenas um trabalho colaborativo e dinâmico, com várias interpretações e análises sistematizadas, sem perder de vista a essência de cada área. 
Como revelado na pesquisa, trata-se de um imperativo histórico, fruto da evolução da sociedade e do processo de construção do conhecimento, e parece estar sendo reivindicada por grande parte dos pesquisadores - neste caso, os estudiosos da cultura, independente da orientação axiológica. Isso porque, como apontado, os estudos particulares não têm dado conta de explicar os fenômenos da pós-modernidade, marcado pela diversidade e hibridização (mistura) cultural.

A praxis interdisciplinar não é, contudo, uma tarefa fácil, pois se assim o fosse, não haveriam tantas práticas e procedimentos, de diferentes bases teóricas, sendo aplicadas em seu nome, gerando, por vezes, até confusão. Tal dificuldade resulta da lógica da pesquisa científica que obedece a um paradigma institucional. Assim como a Igreja Católica, na Idade Média, procedeu, explicitamente, em função da unidade (teocentrismo), contrariando o movimento histórico, que já colocava subsídios para a particularização, a ciência moderna, hoje, tenta manter sua estrutura, focada na especialidade e precisão, engessando as possibilidades de criação humana.

Isso não quer dizer que a ciência tradicional tenha perdido a sua importância, muito menos que as especificidades devam ser desconsideradas, pois, conforme expressa Gaudêncio Frigotto (2011, p. 42) "ainda que se atinja um elevado nível de capacidade crítica, nenhum sujeito individual dá conta de exaurir determinada problemática." O diferencial está, portanto, na forma como o sujeito se relaciona com o objeto, procurando esclarecer e revelar não a sua totalidade, mas, sim, as múltiplas determinações e mediações que o constituem. Em outras palavras, significa ter clareza que um objeto pode ser explorado a partir de múltiplas dimensões: científica, social, política, estética.

A partir desta compreensão, evidencia-se que tanto a disciplinaridade quanto a interdisciplinaridade se impõem, atualmente. São reducionistas, portanto, as concepções que procuram tratar as especificidades como uma espécie de patologia grave que, fatalmente, compromete o processo de construção do conhecimento. $O$ grande cerne da questão não está, portanto, na particularidade, mas nas grandes instituições e personalidades que, ao seu modo, tentam impor o seu modelo de pesquisa científica.

Assim, ao apontar a interdisciplinaridade como imperativo e, ao mesmo tempo, como desafio nos estudos sobre cultura, não cabe responsabilizar o método 
ou a didática, embora, as dificuldades se manifestem, mais enfaticamente, neste nível. O problema parece ser de ordem estrutural, dado o modelo tradicional de ciência que acostumou os pesquisadores a construírem, isoladamente, seus objetos de estudo.

\section{CONCLUSÕES}

A partir das análises realizadas, depreende-se que a interdisciplinaridade é uma imposição do momento atual, nos estudos sobre cultura, já que inexistem justificativas para o estudo em separado desta e da mídia, devido aos efeitos que os meios de comunicação de massa têm provocado nos processos de constituição identitária das nações latino-americanas. Apesar disso, ela se apresenta como um desafio a ser decifrado, fundamentalmente no plano material histórico-cultural, pelas limitações do sujeito que busca construir conhecimento no interior de uma sociedade cindida em classes, cuja estrutura, reflete nos modos de produção científica, não dando conta da complexidade desta realidade, dinâmica e histórica.

Nesse sentido, percebe-se que há, ainda, um grande caminho a ser percorrido e muitas descobertas a realizar, apesar dos grandes avanços já consolidados por meio de abordagens como os Cultural Studies e os Estudos Culturais latino-americanos. Um dos maiores obstáculos a ser superado está relacionado, mais do que a questões didáticas e metodológicas, à rigidez institucional que transforma os campos científicos disciplinares em "prisões" territoriais, cujas barreiras, dificilmente, podem ser ultrapassadas.

Logo, tornar porosas estas fronteiras, promovendo intercâmbios entre visões distintas sobre a cultura constitui, em si, um fator significativo de inovação, capaz de romper com o paradigma da ciência moderna. Para tanto, é preciso respeitar o movimento histórico, deixando o objeto "interculturalidade" falar, o que implica permitir que de dentro do próprio fenômeno da globalização emerjam as indagações sobre o sujeito multicultural, para mais além de paradigmas institucionais. Requer, portanto, converter-se em especialista das interseções, a partir de uma dialética criativa e aberta, pautada na articulação da diferença e não na homogeneidade.

O pesquisador que se dispõe a esta práxis deve, portanto, ter a clareza que a interdisciplinaridade não significa que todos devam saber de tudo, mas que cada um 
pode disponibilizar os seus saberes, em sintonia com os outros, sem deixar de lado a especificidade de cada campo do conhecimento. Deve estar disposto, ainda, ao fracasso de sua expectativa de resultados prontos e positivos, dado o caráter provisório e contingencial da interdisciplinaridade.

A pesquisa teve como objetivo apresentar e refletir acerca da interdisciplinaridade como novo modo de incorporação nos estudos sobre cultura. Isso porque, contemporaneamente, as instituições educacionais têm sido, em grande parte, as agências de transmissão de uma cultura que é dominante, fechada e que tem sido eficazmente cristalizada. A leitura possível, após uma reflexão como a que se apresenta, é a de que o processo epistemológico precisa ser eivado por novas significações, e os Estudos Culturais, apesar das lacunas, podem ser uma alternativa de abordagem que tem como pressuposto a interdisciplinaridade. Assim, a investigação, nesta perspectiva, parece ser uma possibilidade de oposição aos estudos lineares sobre cultura, propondo que se caminhe por novas sendas, agora interdisciplinares. 


\title{
INTERDISCIPLINARITY IN MEDIATIZED SOCIETY: AN IMPERATIVE-PROBLEM DICHOTOMY IN CULTURAL STUDIES
}

\begin{abstract}
:
Through the Cultural Studies perspective, this article analyzes why interdisciplinarity is needed in contemporary society as an imperative and, at the same time, as a challenge. The interdisciplinary approach is a requirement due to the aggravated effects that digital media has led in Latin American nations' identity construction processes and, at the same time, it is a problem as the contemporary theoretical frustrations have not realized how to organize and explain the new diversity. This dichotomy it is not a question of method or didactic, though it manifests with greater emphasis at this level, but fundamentally it is a structural issue, inherited by the traditional model of science that accustomed researchers to build their study objects alone. In this context, the analysis is done within literature and in the path to the qualitative research approach.
\end{abstract}

Keywords: Culture Studies. Culture. Interculturality. Interdisciplinarity. Media.

\section{LA INTERDISCIPLINARIEDAD EN LA SOCIEDAD DE LOS MEDIOS: UNA DICOTOMÍA IMPERATIVO-PROBLEMA EN LOS ESTUDIOS SOBRE CULTURA}

\section{Resumen:}

Este artículo analiza, a través de la perspectiva de los Estudios Culturales, por qué la interdisciplinariedad es un imperativo en la sociedad contemporánea y, al mismo tiempo, un desafío para los estudios sobre cultura. El enfoque interdisciplinario es una exigencia, debido a la influencia que los medios de comunicación han tenido en los procesos de construcción de identidad de las naciones de América Latina. También se presenta como un problema, por las frustraciones teóricas contemporáneas que no han dado cuenta de organizar y explicar nuevas diversidades. Esta dicotomía no es una cuestión de método o didáctica, aunque se manifieste con mayor énfasis en este nivel, sino que fundamentalmente es un problema estructural, heredado del modelo tradicional de la ciencia, que acostumbró a los investigadores a construir aisladamente sus objetos de estudio. Se trata de una investigación bibliográfica, desarrollada en los caminos de la pesquisa cualitativa.

Palabras clave: Estudios Culturales. Cultura. Interculturalidad. Interdisciplinariedad. Medios de comunicación. 


\section{REFERÊNCIAS}

BACHELARD, Gastón. Epistemologia. Barcelona: Ed. Anagrama, 1989.

BIANCHETTI, Lucídio; JANTSCH, Ari Paulo. Imanência, história e interdisciplinaridade. In: BIANCHETTI, L.B; JANTSCH, A.P. (orgs). Interdisciplinaridade para além da filosofia do sujeito. Rio de Janeiro: Vozes, 2011. p.155-170.

BIANCHETTI, Lucídio; JANTSCH, Ari Paulo. Interdisciplinaridade para além da filosofia do sujeito. In: BIANCHETTI, L.B; JANTSCH, A.P. (orgs). Interdisciplinaridade para além da filosofia do sujeito. Rio de Janeiro: Vozes, 2011. p.19-33.

BRONOWSKI, Jacob. O senso comum da ciência. São Paulo : Edusp, 1977.

CANCLINI, Néstor García. Diferentes, Desiguais e Desconectados: Mapas da Interculturalidade. Rio de Janeiro: UFRJ, 2009.

CANCLINI, Néstor Garcia. Culturas Híbridas - estratégias para entrar e sair da modernidade. 4. ed. São Paulo: UNESP, 2011.

CARNEIRO, Marcio. Métodos digitais: a internet e as redes como instrumentos de pesquisa. In: SQUIRRA, S. (Org.). CIBERTECs. São Luiz, MA: LabCom Digital, 2016. Pp.62-87.

COSTA, Marisa Vorraber (Org.). A Educação na cultura da mídia e do consumo. Rio de Janeiro: Lamparina, 2009.

CUCHE, Denys. A noção de cultura nas ciências sociais. São Paulo: EDUSC, 1999.

FRIGOTTO, Gaudêncio. A Interdisciplinaridade como necessidade e como problema nas ciências sociais. In: BIANCHETTI, L.B; JANTSCH, A.P. (orgs). Interdisciplinaridade para além além da filosofia do sujeito. Rio de Janeiro: Vozes, 2011. p.34-59.

GAMBOA, Silvio Sánchez. Pesquisa em Educação: métodos e epistemologias. Chapecó : Argos, 2007. 
GIDDENS, Anthony. Modernidade e Identidade. Rio de Janeiro: Jorge Zahar, 2002.

HALL, Stuart. A identidade cultural na pós-modernidade. 9a Ed. Rio de Janeiro: DP\&A, 2004.

JAMESON, Fredric. A virada cultural: reflexões sobre o pós-modernismo. Rio de Janeiro : Civilização Brasileira, 2006.

KELLNER, Douglas. A cultura da mídia. São Paulo: EDUSC, 2001.

MARTÍN-BARBERO, Jesús. Dos meios às mediações. Rio de Janeiro: UFRJ, 1997.

MARTÍN-BARBERO, Jesús. Tecnicidades, Identidades, Aletriddes: mudanças e opacidades da comunicação no novo século. In: MORAES, Dênis (Org.). Sociedade Midiatizada. Rio de Janeiro : Mauad, 2006.pp.51-80.

MARTÍN-BARBERO, Jesús. Diversidade em convergência. In: MATRIzes. São Paulo - Brasil, v.S, n² 2, jul. dez. 2014. p.15-33.

RAYNAUT, Claude; ZANONI, Magda. Reflexões sobre princípios de uma prática interdisciplinar na pesquisa e no ensino superior. In: SILVA NETO, A. J. \& PHILIPPI A. JR., (Org.). Interdisciplinaridade em ciência, tecnologia \& Inovação. Barueri: Manole, 2011, p. 143-207.

TORDINO, Cláudio Antônio. A Estética do Método. In: FAZENDA, I. C. A. (Org.) Interdisciplinaridade: pensar, pesquisar e intervir.São Paulo: Cortez, 2014, p.2126.

VERÓN, Eliseo. Esquema para el analisis de la mediatización. In: Revista Dialógos de la Comunicación. Lima, 1997.

WILLIAMS, Raymond. Cultura e Materialismo. Tradução André Glaser. São Paulo: UNESP, 2011.

\section{Artigo:}

Recebido em 22 de Fevereiro de 2016.

Aceito em 31 de Janeiro de 2017. 